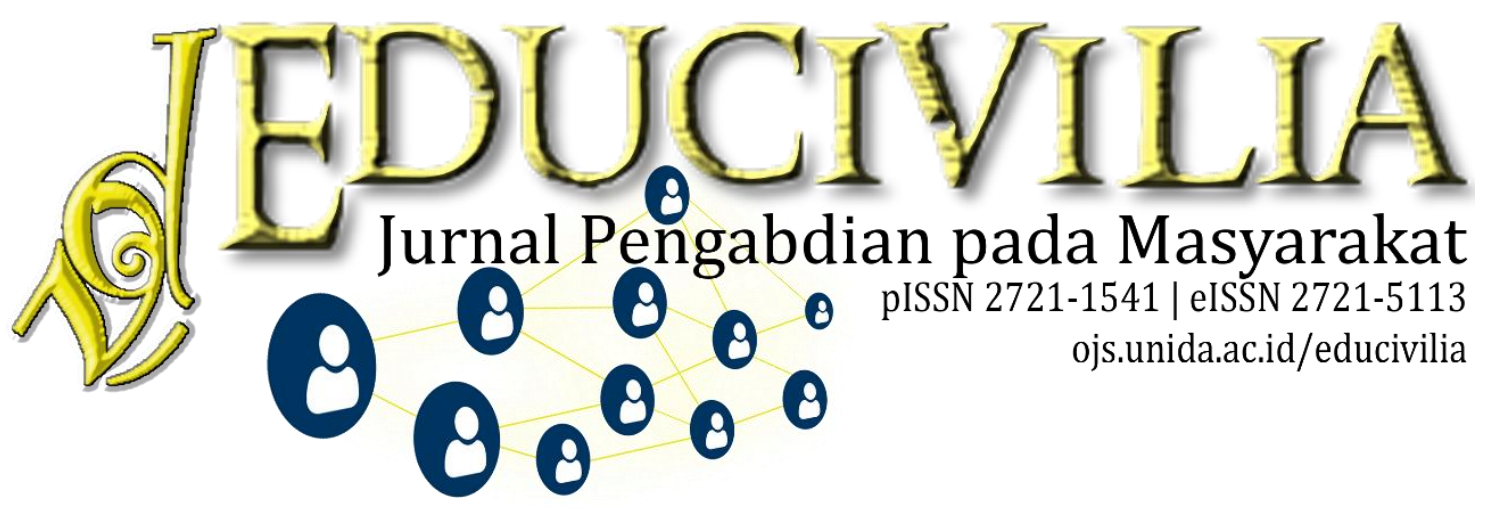

\title{
Program Pondok Ceria Sarana Belajar Menyenangkan Anak-Anak Kampung Pancawati Masa Adaptasi Kebiasaan Baru
}

\author{
Sita Amaliah¹, Teguh Prasetyo², \\ ${ }^{1}$ Program Studi Manajemen Pendidikan Islam, Fakultas Keguruan dan Ilmu Pendidikan, \\ Universitas Djuanda Bogor; Jl. Tol Ciawi No. 1 Kotak Pos 35 Bogor 16720 \\ 2Program Studi Pendidikan Guru Sekolah Dasar, Fakultas Keguruan dan Ilmu Pendidikan, \\ Universitas Djuanda Bogor; Jl. Tol Ciawi No. 1 Kotak Pos 35 Bogor 16720
}

Kilas Artikel

Volume 2 Nomor 1

Januari 2021: 43-50

DOI:

10.30997/ejpm.v\%i\%.3614

Article History

Submission: 30-10-2020

Revised: 10-01-2021

Accepted: 17-01-2021

Published: 26-01-2021

Kata Kunci:

Adaptasi Kebiasaan Baru,

Kuliah Kerja Nyata

(KKN), Merdeka belajar,

Program Pondok Ceria

Keywords:

Adaptation New Habits,

Field Work Experience

$(\mathrm{CCN})$, the Freedom of

learning, Pondok Ceria

Program.

Korespondensi: amaliahsita@gmail.com

\begin{abstract}
Abstrak
KKN pada tahun ini berbeda dengan penyelenggaraan KKN sebelumnya, dikarenakan pandemi Covid-19 yang belum juga usai maka KKN dilaksanakan individu dan pada tempat tinggal masingmasing mahasiswa dengan tema Pemberdayaan pengetahuan melalui program kuliah kerja nyata berbasis adaptasi kebiasaan baru (KKN AKB) untuk mewujudkan merdeka belajar yang menyatu dalam tauhid melalui penyelenggaraan Program Pondok Ceria yang bertempat di Kampung Pancawati RW. 13 Kecamatan Caringin Kabupaten Bogor dengan berbagai macam kegiatan didalamnya guna menunjang merdeka belajar anak-anak dan menambah pengetahuan mereka pada masa adaptasi kebiasaan baru ini, diantara kegiatannya yakni: Literasi baca, one day one hadits (pemberian dan pemahaman hadits-hadits shahih), language in love ( pembelajaran bahasa Arab dan Inggris), ice breaking and games (menyajikan nyanyian serta permainan dan quis), Membuat prakarya( kerajinan-kerajinan dari limbah kain, origami, dan bahan alam), Sabtu minggu sehat (olahraga dan senam pagi). Program ini dapat menunjang terciptanya merdeka belajar anak-anak kampung meskipun pada keterbatasan masa adaptasi kebiasaan baru ini.

The Pondok Ceria Program, a Fun Learning Facility for the Children of Pancawati Village, Adaptation to New Habits Abstract

This KKN is different from the previous KKN because the Covid-19 pandemic has not ended, KKN is carried out individually and at the residence of each student with the theme of Knowledge Empowerment through real work courses based on the adaptation of new habits. (KKN $A K B)$ to realize independent learning that is integrated with tauhid through the implementation of the cheerful cottage program located in Pancawati Village RW13, Caringin District, Bogor Regency with various activities in it to support children's learning freedom and increase their knowledge during the adaptation period of this new habit, including The activities are: Reading literacy, one day hadith (giving and understanding sahih hadith), the language of love (learning Arabic and English), ice breaking and games (presenting songs and games and quizzes), Making crafts (crafts from cloth
\end{abstract}


waste, origami, and natural ingredient), Saturday and Sunday healthy (exercise and morning exercise). This program can support the creation of independent learning for village children even with a limited adaptation period for these new habits.

\section{PENDAHULUAN}

Pelaksanaan Kuliah Kerja Nyata (KKN) merupakan kegiatan Pengabdian pada Masyarakat (PkM) yang ditunggutunggu oleh mahasiswa. KKN pada tahun 2020 diselenggarakan berbeda dengan penyelenggaraan KKN sebelumnya, dikarenakan wabah pandemik Covid-19 yang belum juga usai. KKN mahasiswa dilaksanakan secara individual berdasarkan pada wilayah domisili atau tempat tinggal masing-masing mahasiswa.

Program KKN merupakan salah satu upaya mendukung Kemdikbud, yakni program Merdeka belajar yang dilaksanakan mahasiswa. Adapun tema pengabdian masyarakat mahasiswa yakni "Pemberdayaan Masyarakat melalui program Kuliah Kerja Nyata berbasis Adaptasi Kebiasaan Baru (KKN AKB) untuk mewujudkan merdeka belajar yang menyatu dalam tauhid. Untuk melaksanakan program KKN AKB tersebut tentulah tidak semudah KKN per kelompok karena mahasiswa diharuskan untuk melakukan kuliah kerja nyata secara individu dan di tempat kediaman masing-masing atau di desa masing-masing.

Mahasiswa merupakan change agent karena dapat menjadi penggerak bagi masyarakat yang ada di daerah. Oleh karena itu, implementasi KKN AKB, bentuk penugasan mahasiswa FKIP sebagai fasilitator dan generator untuk menggerakan dan meningkatkan kualitas pendidikan masyarakat (Prasetyo, 2017).

Kampung Pancawati merupakan salah satu kampung yang berada di Desa Pancawati terletak di kaki Gunung Pangrango Kabupaten Bogor, pada masa adaptasi kebiasaan baru ini perekonomian di Kampung Pancawati terbilang agak sulit dikarenakan mayoritas pekerjaan masyarakat sebagai petani dan kuli tani serta permintaan pasar cenderung menurun dan tidak seperti biasanya, selain itu yang terkena dampak paling besar adalah lembaga pendidikan karena mengharuskan siswa-siswinya untuk belajar online sementara dari rumah dan hal tersebut 
merupakan hal yang terbilang sulit dikarenakan keterbatasan jaringan yang sulit didapat dikampung ini serta alat penunjang seperti handphone yang masih minim dimiliki oleh para siswa dan orang tua siswa hal ini juga di latar belakangi oleh kurangnya tenaga pendidik dari setiap lembaga.

Pendidikan merupakan proses belajar mengajar yang menghasilkan perubahan tingkah laku yang diharapkan yang meliputi beberapa aspek antara lain aspek keagamaan, aspek kesejahteraan, aspek kebahasaan, aspek ruang lingkup, dan aspek tanggung jawab (Heryati \& Muhsin, 2014).

Maka dari itu penulis melaksanakan pengabdian masyarakat atau kegiatan KKN AKB ini di kampung penulis sendiri yaitu di Kampung Pancawati RW 13, Desa Pancawati, Kecamatan Caringin, Kabupaten Bogor berharap dapat membantu menunjang pemberdayaan pengetahuan masyarakat khususnya anak-anak desa mengenai pendidikan serta kesehatan dan pemahaman mengenai covid-19 pada masa adaptasi kebiasaan baru ini.

METODE
Metode yang digunakan untuk membantu mengatasi permasalahan tersebut adalah dengan terjun langsung ke lapangan untuk mengamati secara langsung tempat pelaksanaan $\mathrm{KKN}$ AKB, kegiatan-kegiatan dan permasalahan-permasalahan yang ada. Penulis melakukan observasi dan wawancara juga melakukan koordinasi bersama Kepala Desa, ketua RW, RT, dan Satuan Kepala Pendidikan, serta pihak-pihak lain yang terkait terkait program yang akan dilaksanakan serta membuat dan menyediakan tempat serta sarana program Pondok Ceria.

Dengan program Pondok Ceria diharapkan dapat membantu pemberdayaan pengetahuan masyarakat terutama usia anak-anak sekolah yang masih memiliki kesempatan lebih banyak untuk belajar serta menggali pengetahuan sebanyak mungkin. Anakanak dan kelompok masyarakat di Kampung Pancawati dapat tetap menjalankan aktivitas produksi (produktif) dan tetap sehat di era pandemic Covid-19 (Irawan, Triana, Suwarni, \& Selviana, 2020).

Program Pondok Ceria memiliki sarana lemari berisi buku-buku pelajaran serta buku-buku bacaan serta 
Program Pondok Ceria Sarana Belajar Menyenangkan ...

tempat baca dan dinding kreasi, anakanak desa hanya tinggal datang membawa peralatan tulis ke tempat Pondok Ceria yang telah tersedia. Informasi kegiatan program Pondok Ceria ini disebarluaskan pada masyarakat sekitar khususnya untuk anak-anak kampung melalui door to door serta mulut ke mulut oleh anak-anak serta masyarakat.

\section{HASIL \& PEMBAHASAN}

Pada masa Pandemi saat ini segala bentuk kegiatan harus dilaksanakan dari rumah bagi anak tingkat SD dan SMP, termasuk anak-anak di Kampung Pancawati RW 13 Kecamatan Caringin Kabupaten Bogor. Salah satu contoh belajar yang digunakan sekarang ini yakni Pembelajaran Jarak Jauh (PJJ) bagi setiap instansi pendidikan. Hal ini mendorong untuk terselenggaranya kegiatan pengabdian masyarakat, khususnya bagi setiap anak dan para orang tua (Nurohmah, Aini, Kholik, \& Maryani, 2020). Hal tersebut membantu pelaksanaan program pemerintah dalam memutus rantai penularan covid19 dan tetap mampu melaksanakan kegiatan pembelajaran walaupun dari rumah.
Penyelenggaraan suatu Program Pemberdayaan pengetahuan anak-anak di Kampung Pancawati RW 13 Kecamatan Caringin Kabupaten Bogor yang diberi nama Program Pondok Ceria (Cerdas Riang Gembira) merupakan sarana untuk menunjang serta membantu mengatasi permasalahan pendidikan yang terjadi pada masa pandemik di Kampung Pancawati tersebut. Dalam UndangUndang SISDIKNAS pasal 6 bab hak dan kewajiban warga Negara disebutkan bahwa "Setiap warga Negara bertanggung jawab terhadap keberlangsungan penyelenggaraan pendidikan" (Perundang-Undangan, 2013).

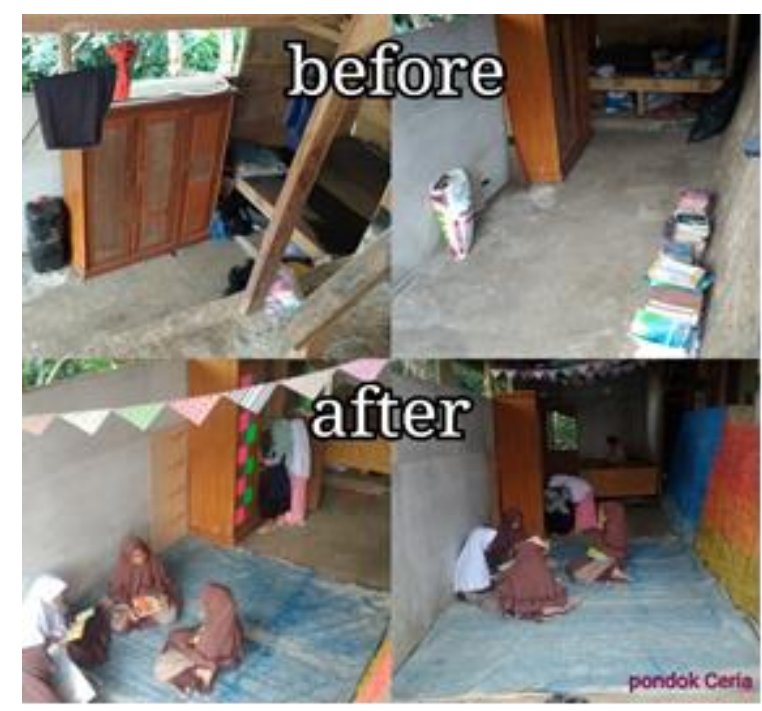

Gambar 1 Kondisi Lokasi Pondok Ceria Sebelum dan Sesudah

Program Pondok Ceria ini bertempat di belakang rumah yang 
berawal dari sebuah gudang kini menjadi pondok belajar untuk anakanak sekitar yang di beri nama pondok ceria. Penyelenggaraan program ini bekerja sama dengan Keluarga sebagai penyedia tempat dan Bapak RT. serta masyarakat yang sudah membantu dalam proses pendirian program ini.

Program Pondok Ceria ini memiliki lemari ajaib yang berisikan buku-buku pelajaran SD-SMA, kamus \& kitab, serta buku-buku cerita atau bacaan untuk menunjang minat baca serta literasi baca anak-anak desa tersebut, selain kegiatan literasi baca, kegiatan program Pondok Ceria diantaranya:

1. One day one hadits yaitu pemberian Pembelajaran Hadits setiap harinya agar anak-anak mengetahui serta memahami mengenai hal-hal yang mereka lakukan sesuai ajaran Islam,

2. Language in love yaitu Pemberian kosa kata Bahasa Arab dan bahasa Inggris dengan metode menyenangkan, seperti bernyanyi dan bermain peraga untuk menambah kemampuan bahasa asing,

3. Ice breaking and games yaitu bermain permainan edukasi dan permainan tradisional di tengah atau di akhir pembelajaran,

4. Membuat prakarya yaitu pengajaran dan penyediaan fasilitas pembuatan kesenian dan kerajinan tangan dari origami, limbah kain, bahan alam sehingga anak-anak bebas berkreasi,

5. Sabtu Minggu sehat yaitu program kesehatan yang dilakukan setiap hari Sabtu dan Minggu pagi bersama anak-anak lari pagi atau jalan santai mengitari perkampungan serta melakukan senam pagi.

Kegiatan-kegiatan tersebut membantu dalam menghadapi tantangan global yang dihadapi oleh pendidikan salah satunya yaitu: "menggunakan sistem pendidikan tidak hanya memindahkan batang tubuh keilmuan secara umum, tetapi melestarikan berbagai warisan budaya, bahasa seni, gaya hidup di dunia yang semakin homogen (Nanang, 2013). Pembelajaran bahasa Arab dan Inggris menggunakan metode yang menyenangkan sangat membantu anakanak belajar. Senada yang dikemukakan oleh bahwa pembelajaran bahasa Inggris dapat dilakukan melalui aktivitas indoor dan outdoor seperti 
Program Pondok Ceria Sarana Belajar Menyenangkan ...

kegiatan menyanyi, bercerita, Tanya dan jawab mendengarkan audio, permainan, dan mengerjakan projek (Rabbiyanti, 2015).

Pelaksanaan program Pondok Ceria ini dimulai pukul 13.00 s.d 14.30 untuk anak-anak kelas PAUD dan anak-anak kelas 1-3 SD, dilanjutkan pukul 15.30 s.d. 17.30 untuk anak-anak kelas 4-6 SD dan anak-anak SMP. Pelaksanaan Program Pondok Ceria diawali dengan Pembacaan doa, literasi baca, Murojaah hadits dan kosa kata, penambahan hadits dan kosa-kata baru. Kegiatan ini diselipkan dengan pemberian pemahaman makna hadits, menghafal bersama, ice breaking and games, pembuatan prakarya dan ditutup dengan doa bersama.

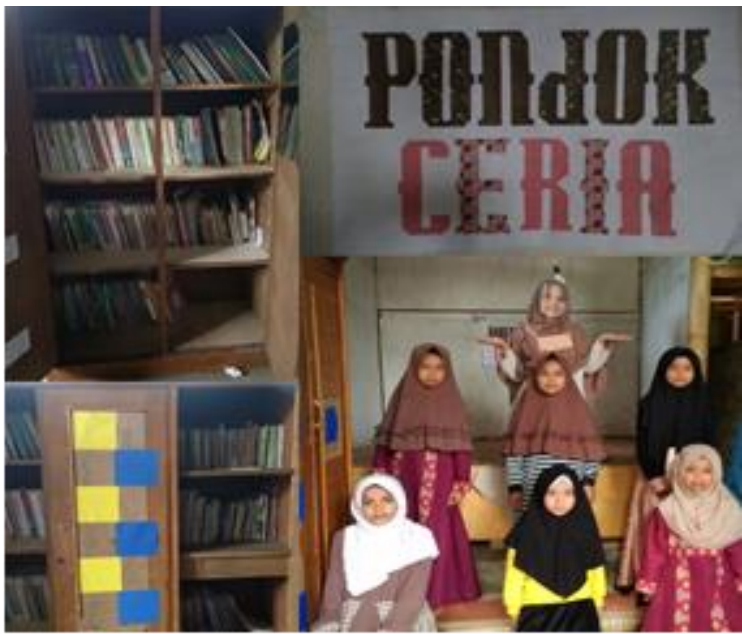

Gambar 2 Suasana Pondok Ceria sebagai Literasi Bacaan Anak di Masa Adaptasi Kebiasaan Baru (AKB)

Program Pondok Ceria ini memiliki tujuan untuk mengisi waktu luang anak-anak kampung Pancawati dengan kegiatan yang positif yakni belajar bersama dengan metode menyenangkan, menumbuhkan kecintaan baca anakanak kampung Pancawati dan kecintaan belajar bahasa asing serta menumbuhkan kreativitas dan semangat belajar anak-anak pada masa adaptasi kebiasaan baru ini.

Dampak hasil pelaksanaan Pondok Ceria di Kampung Pancawati diantaranya: (a) Menumbuhkan minat baca anak-anak, (b) Semakin kuatnya daya tangkap dan daya ingat anak-anak, (c) Bertambahnya pengetahuan, dan pemahaman mengenai Hadits dan Mahfudzot, (d) Bertambahnya kosa kata bahasa Arab dan bahasa Inggris yang anak-anak ketahui, (e) Mengembangkan Kreativitas anak-anak yang semakin tumbuh dan berkembang, Mengetahui pentingnya berolahraga dan menjaga kesehatan pada masa Adaptasi Kebiasaan Baru ini. Pondok Ceria di Kampung Pancawati merupakan salah satu contoh dari pengabdian dibidang pendidikan khususnya membaca bagi masyarakat. Bentuk lain seperti taman bacaan masyarakat sangat memberikan dampak positif dan membantu dalam 
meningkatkan gemar membaca khususnya anak-anak (Dwiyantoro, 2019), dapat menjadi tempat yang kondusif untuk membangun generasi cerdas dan unggul di desa serta meningkatkan literasi masyarakat (Basalamah, \& Rizal, 2020).

Alhamdulillah, penyelenggaraan program Pondok Ceria selama kurang lebih satu bulan ini berjalan dengan baik dan lancar, sudah mulai terlihat anakanak yang mulai gemar membaca setiap sore dan antusias mereka (anak-anak) dalam mengikuti program tersebut. Masyarakat khususnya anak-anak kampung Pancawati berharap agar program Pondok Ceria ini bisa terus berjalan seterusnya, dan insyAllah program pondok ceria akan terus berdiri dan terbuka untuk masyarakat dengan waktu pembelajaran setiap Minggu.

\section{SIMPULAN}

Program Pondok Ceria merupakan salah satu program KKN AKB yang dilaksanakan di Kampung Pancawati RW. 13 Kecamatan Caringin Kabupaten Bogor. Program Pondok Ceria merupakan program penunjang pemberdayaan pengetahuan masyarakat anak-anak kampung Pancawati dalam menumbuhkan minat baca anak-anak serta literasi baca, menambah pengetahuan sosial dari apa yang telah mereka baca dan mereka dengar dari beberapa cerita yang telah disampaikan setiap harinya, menambah kecintaan terhadap bahasa Arab dan bahasa Inggris, membuat anak-anak mengetahui dan memahami haditshadits shahih mengenai kegiatan seharihari, membuat anak-anak lebih bersemangat belajar karena sambil bermain, menumbuhkan kreativitas dan melatih keterampilan anak-anak.

\section{UCAPAN TERIMA KASIH}

Pada kesempatan yang baik ini, izinkanlah penulis menyampaikan rasa hormat dan ucapan terima kasih kepada semua pihak yang dengan tulus ikhlas telah memberikan bantuan dan dorongan kepada penulis dalam menyelesaikan laporan ini, terutama kepada: Kedua Orang tua serta keluarga yang telah mendukung penuh kegiatan pelaksanaan KKN AKB ini, Kepada Dosen Pembimbing Lapangan dan seluruh staf serta dosen Fakultas Keguruan dan Ilmu Pendidikan Universitas Djuanda Bogor, Kepada bapak kepala desa Pancawati dan seluruh staff, Kepada bapak RW dan RT 
Kampung pancawati, Kepada Guruguru MI Al-Aziziyah dan PAUD Nanda, serta seluruh masyarakat Pancawati yang saya hormati dan banggakan.

\section{DAFTAR PUSTAKA}

Basalamah, M. R., \& Rizal, M. (2020). Penyediaan Rumah Baca Masyarakat Sebagai Solusi Cerdas Mengawali Budaya Membaca. Dinamisia: Jurnal Pengabdian Kepada Masyarakat, 4(1), 36-42.

Dwiyantoro, D. (2019). Peran Taman Bacaan Masyarakat Mata Aksara dalam menumbuhkan minat baca pada masyarakat. Jurnal Kajian Informasi E Perpustakaan, 7(1), 19-32. Heryati, Y., \& Muhsin, M. (2014). Manajemen sumber daya pendidikan. Bandung: CV Pustaka Setia.

Irawan, D., Triana, N., Suwarni, L., \& Selviana, S. (2020). Edukasi protokol kesehatan dan strategi pemasaran online melalui program kemitraan masyarakat di era pandemi COVID-19. JMM (Jurnal Masyarakat Mandiri), 4(4), 655-662.

Nanang, F. (2013). Analisis Kebijakan. Pendidikan. Bandung: PT. Remaja Rosdakarya.

Nurohmah, R., Aini, N., Kholik, A., \& Maryani, N. (2020). Literasi Media Digital Keluarga di Tengah Pandemi COVID-19. Educivilia: Jurnal Pengabdian pada Masyarakat, 1(2), 159-168.

Perundang-Undangan, H. P. (2013). Undang-undang sisdiknas. Bandung: Fokus Media.

Prasetyo, T. (2017). Improving the quality of islamic education through the role of students.
Qardhul Hasan: Media Pengabdian kepada Masyarakat, 2(1), 35-42.

Rabbiyanti, E. N. (2015). Pembelajaran Bahasa Inggris pada Anak Usia Dini di Sekolah Alam Exelentia Pamekasan Madura. OKARA: Jurnal Bahasa dan Sastra, 9(1), 83-102. 